\title{
Evidência molecular da ocorrência de um fitoplasma associado ao lenho mole da macieira
}

\author{
Luiz Fernando Caldeira Ribeiro ${ }^{1}$, Ivan Paulo Bedendo ${ }^{1}$, Rosa Maria Valdebenito Sanhueza ${ }^{2}$
}

\author{
${ }^{1}$ Setor Fitopatologia / ESALQ-USP, Av. Pádua Dias, 11 CEP 13418-900 Piracicaba /SP, e-mail: ipbedend @ esalq.usp.br, ${ }^{2}$ Embrapa Uva e Vinho, \\ rua Livramento, 515, CEP 95700-000 Bento Gonçalves, RS. \\ Autor p/ correspondência: Ivan Paulo Bedendo \\ Data de chegada: 15/08/2005. Aceito para publicação em: 04/05/2006.
}

\section{RESUMO}

Ribeiro, L.F.C.; Bedendo, I.P.; Sanhueza, R.M.V. Evidência molecular da ocorrência de um fitoplasma associado ao lenho mole da macieira. Summa Phytopathologica, v.33, n.1, p.30-33, 2007.

O lenho mole da macieira é uma doença relevante em diversas partes do mundo. Sintomas típicos desta doença têm sido observados em pomares instalados em estados do sul do território brasileiro desde a década de oitenta. Enxertia tem revelado a natureza infecciosa da doença e a observação de corpúsculos filamentosos no floema tem evidenciado possível associação com fitoplasma. No presente trabalho plantas com sintomas de lenho mole foram coletadas em pomar comercial, visando demonstrar a presença de fitoplasma em tecido doente, bem como identificar molecularmente este fitoplasma. Através do emprego de duplo PCR com iniciadores universais R16mF2/R1 e R16F2n/R2, fitoplasma foi consistentemente detectado em plantas sintomáticas. A identificação conduzida com duplo PCR usando-se iniciadores específicos R16(III)F2/ $\mathrm{R}$ demonstrou que o fitoplasma detectado pertencia ao grupo 16SrIII. Análises de RFLP conduzidas com as endonucleases AluI, KpnI, HinfI, HpaII, MseI, RsaI e SauIIIA confirmaram que o fitoplasma era um representante típico do grupo 16 SrIII. A detecção e identificação molecular se constitui numa forte evidência que um fitoplasma está associado ao lenho mole da macieira no Brasil, complementando os trabalhos realizados anteriormente com transmissão por enxertia e observação por microscopia eletrônica .

Palavras-chave adicionais: molicutes, procariotos fitopatogênicos, doenças fitoplasmáticas. \begin{abstract}
Phytopathologica, v.33, n.1, p.30-33, 2007.
Apple rubbery wood is an important disease occurring worldwide. Typical symptoms have been observed since $80^{\prime}$ ' decade in orchards located in the South part of Brazil. In previous studies, grafting has evidenciated that the disease had infeccious etiology and visualization of filamentous bodies inside phloem had indicated that a phytoplasma could be associated with the disease. In the present study, plants with symptoms of rubbery wood were sampled in a commercial orchard in order to demonstrate the presence of phytoplasma in infected tissue and to identify molecularly that the organism. Using nested PCR with universal primers pairs R16mF2/
\end{abstract}

ABSTRACT

Ribeiro, L.F.C.; Bedendo, I.P.; Sanhueza, R.M.V. Molecular evidence for an association of a phytoplasma with apple rubbery wood. Summa

$\mathrm{R} 1$ and $\mathrm{R} 16 \mathrm{~F} 2 \mathrm{n} / \mathrm{R} 2$, phytoplasma was consistently detected in symptomatic plants. Identification conducted with specific primer pair R16(III)F2/R1 in nested PCR demonstrated that the phytoplasma was a member of group 16SrIII. RFLP analyses with endonucleases AluI, KpnI, HinfI, HpaII, MseI, RsaI e SauIIIA confirmed that the phytoplasma was a representative of the group 16 SrIII. The detection and molecular identification are strong evidences that a phytoplasma is associated with apple rubbery wood in Brazil and agrees with previous evidences using grafting and electron microscopy.

Additional keywords: Mollicutes, phytophathogenic prokaryontes, phytoplasmal diseases.

Típica espécie de clima temperado, a maçã é de relevante importância econômica na fruticultura brasileira, sendo os maiores pomares encontrados em Santa Catarina e no Rio Grande do Sul, respondendo por mais de $90 \%$ da produção nacional (1).

Dentre os problemas fitossanitários da cultura estão o superbrotamento e o lenho mole, ambos associados a fitoplasmas, e presentes em várias partes do mundo (20). O lenho mole tem ampla distribuição no continente europeu, sendo sua ocorrência registrada em diversos países como Alemanha, República Tcheca, França, Hungria $(3,9,17)$. Existem ainda relatos na Índia, África do Sul, Austrália, México, Estados Unidos, Canadá e países da Ásia (11, 17). Na França, a incidência chega a $30 \%$, enquanto na Nova Zelândia este índice alcança até $75 \%$ das plantas cultivadas (8).

Os sintomas típicos se manifestam principalmente nos ramos, os quais se apresentam extremamente flexíveis e facilmente dobráveis, devido à alteração na formação de lignina. São comuns também os 
sintomas de encurtamento de internódios, formação de ramos achatados, redução do crescimento da planta e diminuição no tamanho de frutos. A redução na produção pode variar de 25 a $50 \%$, enquanto o vigor da planta pode ser reduzido de 10 a $50 \%$ (8). No Brasil, levantamentos feitos nos estados do Rio Grande do Sul, Santa Catarina e Paraná apontaram incidências variáveis de 1 a $50 \%$ em pomares comerciais (5). A doença também foi encontrada em pomares instalados no estado de São Paulo, porém na forma latente e com baixo nível de incidência $(4,7)$.

O primeiro registro sobre a doença foi feito na Inglaterra, na década de quarenta (3). Inicialmente, foi atribuída a vírus devido à sintomatologia e à forma de transmissão do possível agente causal, porém, posteriormente a doença foi associada a fitoplasma, através de microscopia eletrônica (2).

Relatos sobre a ocorrência do lenho mole da macieira no Brasil foram feitos no início da década de oitenta, quando testes de transmissão por enxertia evidenciaram a passagem de um possível agente infeccioso de plantas sintomáticas para plantas indicadoras das variedades Lord Lambourne, Gala e Golden Delicius $(4,5,6)$. Evidências da associação entre lenho mole e fitoplasmas foram demonstradas através de microscopia eletrônica pela visualização de corpúsculos filamentosos no floema de plantas amostradas no sul do território brasileiro (22). Estas evidências foram confirmadas, posteriormente, com o emprego da técnica conhecida por DAPI (21). Apesar destes resultados, nenhuma evidência molecular foi relatada, até o presente momento, de associação de fitoplasmas ao lenho mole em amostras obtidas de pomares nacionais. No entanto, na Europa, testes de detecção através da técnica de PCR simples evidenciaram que a doença não estava associada a fitoplasma (19). Contudo, anos mais tarde, um outro grupo de pesquisadores investigou o mesmo assunto e, usando a técnica de PCR duplo, confirmou a presença de um fitoplasma do grupo 16SrI em plantas que exibiam sintomas de lenho mole, cultivadas na Europa (3).

Em razão de sintomas típicos de lenho mole terem sido observados em pomares brasileiros de maçã, o presente trabalho teve por objetivos: demonstrar molecularmente a associação de fitoplasma com a doença e identificar, com base molecular, este fitoplasma, determinando sua classificação em um dos grupos atualmente reconhecidos para classificação destes molicutes.

\section{MATERIAL E MÉTODOS}

\section{Coleta de amostras de plantas de maçã}

Amostras de ramos novos e de raízes secundárias de plantas de maçã da variedade Gala foram coletadas de três plantas (P1, P2 e P3) exibindo sintomas típicos de lenho mole. O pomar amostrado estava implantado na região de Vacaria (RS). As amostragens, em número de nove, foram realizadas em diferentes meses do ano de 2000, ou seja janeiro, fevereiro, março, abril, junho, julho, agosto, setembro e outubro.

\section{Condições de PCR}

A partir de cada amostra foi obtido o DNA total para ser utilizado nas reações de PCR. A extração foi conduzida de acordo com protocolo descrito pela literatura (14). A detecção de fitoplasma foi conduzida através de duplo PCR usando-se os pares de iniciadores (primers) universais R16mF2/R1 e R16F2n/R2, baseados no 16S rDNA (12). Os produtos amplificados pelo primeiro par foram diluídos (1:50) em água destilada-deionizada e usados na re-amplificação pelo segundo par de iniciadores. As reações foram conduzidas em termociclador automático programado para 35 ciclos, sendo que cada ciclo compreendeu uma etapa de desnaturação a $94^{\circ} \mathrm{C}$ por 1 minuto, anelamento a $50^{\circ} \mathrm{C}$ por 2 minutos e extensão a $72^{\circ} \mathrm{C}$ por 3 minutos. Uma etapa inicial de 1 minuto a $94^{\circ} \mathrm{C}$ e uma final a $72^{\circ} \mathrm{C}$ por 7 minutos foram processadas (14).

Os produtos de PCR foram submetidos a eletroforese em gel de agarose $1 \%$ e, após coloração com brometo de etídeo, as bandas foram visualizadas em transiluminador de luz ultravioleta. Os padrões positivos foram representados por DNA de planta de chuchu e milho, infectadas, respectivamente, pelos fitoplasmas do superbrotamento e do enfezamento. DNA de planta de maçã sadia e água representaram os padrões negativos. O marcador molecular foi $1 \mathrm{~kb}$ ladder (Life Technologies).

\section{Identificação de fitoplasma por PCR}

Para a identificação, os produtos de PCR amplificados pelos iniciadores $\mathrm{R} 16 \mathrm{mF} 2 / \mathrm{R} 1$ foram diluídos 1:50 em água destiladadeionizada e re-amplificados pelos iniciadores R16(III)F2/R1(15), específicos para identificação de fitoplasmas do grupo 16SrIII. O DNA obtido de plantas de chuchu infectadas por um fitoplasma do grupo 16SrIII serviu como padrão positivo. As condições de PCR e eletroforese foram idênticas àquelas descritas anteriormente (14). O padrão de massa molecular utilizado foi $1 \mathrm{~kb}$ ladder.

\section{Análise de RFLP}

A identificação de fitoplasma também foi feita por RFLP, com base nos perfis eletroforéticos obtidos pela digestão enzimática dos produtos amplificados pelo duplo PCR, conduzido com os iniciadores universais. Fragmentos de DNA de 1,2kb foram digeridos, pelas endonucleases AluI, KpnI, HinfI, HpaII, MseI, RsaI e SauIIIA, de acordo com a recomendação dos fabricantes. Os produtos de digestão foram analisados por eletroforese usando-se gel de poliacrilamida $4,5 \%$, colorido em brometo de etídeo e visualizado em transiluminador de ultra-violeta. Amplificações obtidas a partir de DNA de chuchu infectado por fitoplasma do grupo $16 \mathrm{SrIII}$ foram usadas como padrões para cada uma das endonucleases. O marcador molecular foi FX174RFHaeIII. O perfil eletroforético obtido para cada enzima foi comparado aos padrões existentes na literatura (16), visando determinar a classificação do fitoplasma em um dos grupos atualmente adotados para estes microrganismos.

\section{RESULTADOS E DISCUSSÃO}

Com base na amplificação do $16 \mathrm{~S}$ rDNA empregando-se os pares de iniciadores universais em PCR duplo, fitoplasma foi detectado em plantas de maçã que apresentavam sintomas de lenho mole (Figura 1). A presença de fitoplasma foi revelada pela visualização de bandas de aproximadamente $1,2 \mathrm{~kb}$, típicas para fitoplasmas quando são usados os iniciadores R16F2n/R2 (12). Amplificações também ocorreram para DNA extraído de planta de chuchu usada como padrão positivo, no entanto nenhuma amplificação ocorreu para os padrões negativos representados por DNA de planta de maçã assintomática e água. Os resultados foram consistentemente confirmados pela repetição dos testes de PCR.

A dectecção de fitoplasma foi feita tanto em amostras de ramos como de raízes, sendo que ambos os materiais propiciaram bons resultados. Assim, recomenda-se a coleta de ramos novos para confirmação da presença de fitoplasma em planta sintomática, devido a maior facilidade para amostragem. O uso de duplo PCR revelou a presença consistente de fitoplasma em tecidos de plantas sintomáticas 


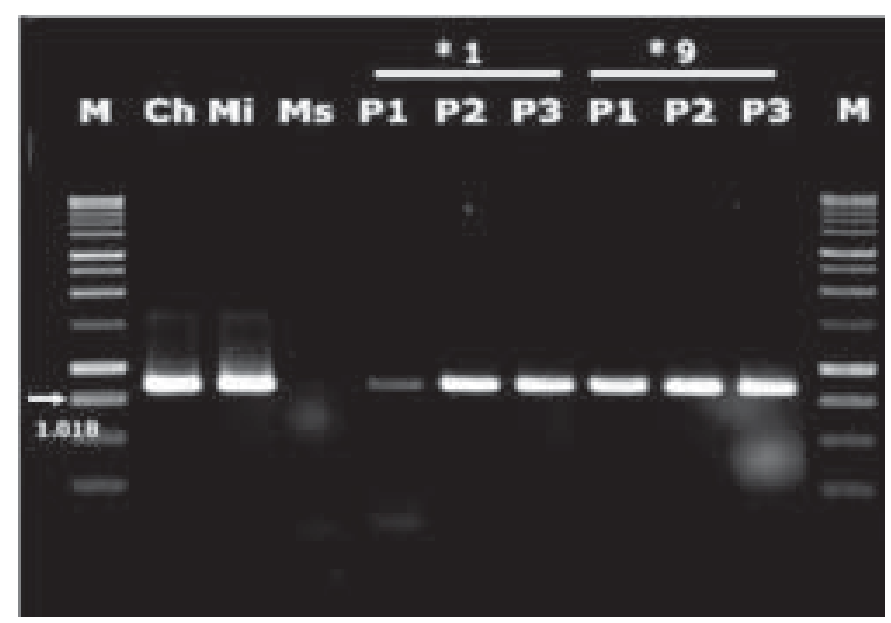

Figura 1. Detecção molecular de fitoplasma por duplo PCR em amostras de raízes de plantas sintomáticas, usando iniciadores universais $\mathrm{R} 16 \mathrm{mF} 1 /$ $\mathrm{R} 1$ e R16F2n/R2. $\mathrm{M}=$ marcador molecular; $\mathrm{Ch}=$ chuchu (padrão); $\mathrm{Mi}=$ milho (padrão); Ms= maçã sadia; P1, P2 e P3= plantas sintomáticas de maçã; $* 1$ e $* 9=$ amostras coletadas em janeiro e outubro de 2002, respectivamente.

coletadas no território brasileiro, assim como demonstrado para plantas de maçã cultivadas no continente europeu e apresentando a mesma sintomatologia (3). Em ambos os casos, a técnica de duplo PCR mostrou-se eficiente para demonstrar a associação de fitoplasma com plantas doentes sendo recomendável, portanto, em relação ao PCR simples, o qual não se mostrou apropriado para evidenciar a ocorrência de fitoplasma em tecidos de plantas que exibiam sintomas de lenho mole (19).

Os resultados do presente trabalho, empregando técnica molecular, demonstraram a ocorrência de um fitoplasma associado ao lenho mole em pomares brasileiros, complementando investigações anteriores. Estudos conduzidos na década de oitenta evidenciaram a natureza infecciosa da doença, pois material de plantas doentes produziram sintomas em plantas testes sadias através de enxertia (6). Ainda, evidências de que o agente pudesse ser um fitoplasma foram produzidas pela observação de corpúsculos no floema de tecidos de plantas doentes, através de técnicas microscópicas (21,22). Assim, a detecção molecular vem fechar este ciclo de estudo.

A identificação de fitoplasma através de duplo PCR, usando-se o par de iniciadores específicos, permitiu demonstrar a presença de um fitoplasma afiliado ao grupo 16 SrIII. Neste caso, bandas de aproximadamente $0,8 \mathrm{~kb}$ foram visualizadas confirmando que o fitoplasma era um membro do grupo $16 \mathrm{SrIII}$, de acordo com os padrões estabelecidos (15). Banda de $0,8 \mathrm{~kb}$ também foi observada para amostra de chuchu sabidamente infectada por um fitoplasma do grupo $16 \mathrm{Sr}$ III, confirmando o resultado obtido para o fitoplasma detectado em material de maçã.

As análises de RFLP (Figura 2) revelaram, para todas as enzimas de restrição, que o fitoplasma detectado em plantas de maçã apresentou padrões eletroforéticos típicos dos fitoplasmas do grupo 16SrIII, como especificado pela literatura (16). Os fitoplasmas provenientes de cada uma das três plantas amostradas (P1, P2 e P3) apresentaram perfis eletroforéticos idênticos entre si, para cada uma das endonucleases, confirmando que o fitoplasma associado aos sintomas exibidos pelas plantas amostradas é um membro do grupo 16SrIII. Diferentemente dos resultados deste trabalho, foi demonstrado que o fitoplasma do lenho mole encontrado na Europa pertence ao grupo 16SrI (3). Este fato não
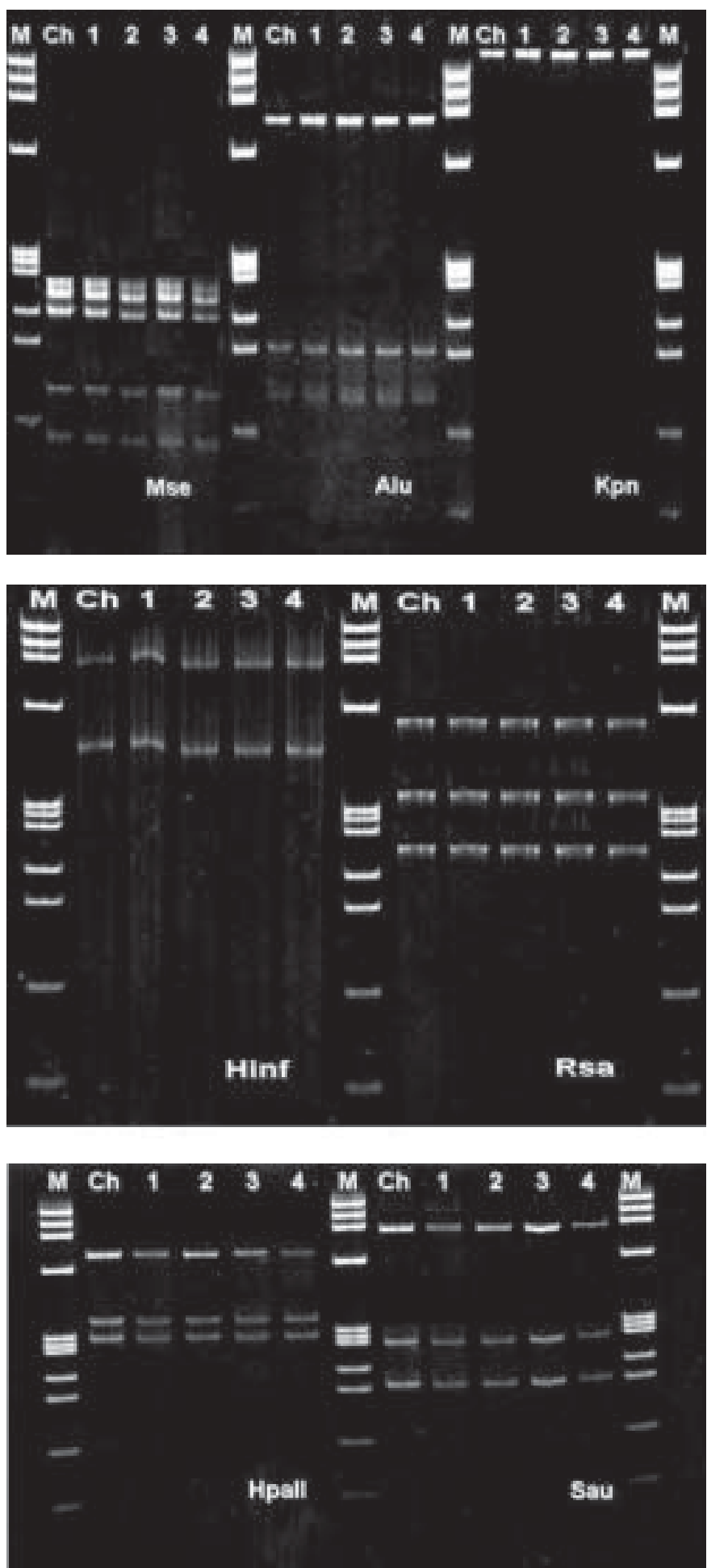

Figura 2. Análise de RFLP de produtos de PCR amplificados pelos iniciadores R16F2n/R2 e digeridos pelas endonucleases MseI, AluI, KpnI, HinfI, RsaI, HpaII e Sau3AI. M= marcador molecular; $\mathrm{Ch}=$ chuchu (padrão); 1, 2, 3= amostras de ramos de plantas sintomáticas; 4= amostra de raiz de planta sintomática.

se constitui em novidade, visto que para outros patossistemas, fitoplasmas distintos podem infectar uma mesma espécie botânica, como demonstrado para o cálice gigante do tomateiro (10), amarelos da videira (18) e para enfezamentos em algumas espécies silvestres (13). Além dos perfis obtidos para as diversas enzimas terem sido 
típicos de fitoplasma do grupo 16SrIII, a constatação de que a enzima KpnI não promoveu a digestão do produto amplificado pelo PCR é uma comprovação de que o fitoplasma encontrado em plantas de maçã cultivadas no Brasil pertence ao grupo $16 \mathrm{Sr}$ III e não ao grupo $16 \mathrm{SrI}$, de acordo com os padrões adotados para classificação de fitoplasmas (16).

O presente trabalho resultou na identificação molecular de um fitoplasma do grupo 16SrIII associado ao lenho mole da macieira no Brasil e complementou as evidências relatadas em outras pesquisas de que esta doença da macieira é de etiologia infecciosa.

\section{REFERÊNCIAS BIBLIOGRAFICAS}

1.Agrianual 2002: Anuário da Agricultura Brasileira. São Paulo: FNP. $377 \mathrm{p}$.

2.Beakbane, A.B.; Mishra, M.D.; Posnette, A.F.; Slater, C.H.W. Mycoplasma-like organisms associated with chat fruit and rubbery wood disease of apple (Malus domestica Borkh.) compared with those in strawberry with green petal disease. Journal of General Microbiology, Reading, v.66, p.55-62, 1971.

3.Bertaccini, A.; Vibio, M.; Franova, J.; Janeckova, M.; Hadidi, A. Molecular detection of phytoplasmas in apple with rubbery wood symptoms. Acta-Horticulturae, The Hague, v.472, p.693-700, 1998.

4.Betti, J.A. Presença do lenho mole da macieira no estado de São Paulo. Summa Phytopathologica, Botucatu, v.8, n.1, p.29-30, 1982.

5.Betti, J.A. ; Kitajima, E.W. Lenho mole, uma doença da macieira no sul do Brasil semelhante ao apple rubbery wood. Summa Phytopathologica, Botucatu, v.7, n.1, p. 9, 1981.

6.Betti, J.A.; Bleicher, J.; Costa, A.S. Transmissão do lenho mole da macieira por união de tecidos. Fitopatologia Brasileira, Lavras, v.7, n.1, p.148, 1982

7.Betti, J.A.; Castro, J.L.; Muller, G.W. Presença do agente causal do lenho mole em plantas sem sintomas em macieira no estado de São Paulo. Fitopatologia Brasileira, Lavras, v.11, n.3, p.366, 1986.

8.Bleicher, J. Doenças da macieira e outras pomáceas. In: Kimati, H.; Amorim, L. Bergamin Filho, A., Camargo, L. E. A.; Rezende, J. A. M. Manual de fitopatologia: doenças das plantas cultivadas. São Paulo; Editora Agronômica Ceres, 1997. v.1, p.473-474.

9.Del Serrone, P.; Starza. S.; Krystai, L.; Kolber, M.; Barba, M. Occurrence of apple proliferation and pear decline phytoplasmas in diseased pear trees in Hungary. Journal Plant Pathology, Wageningen, v.80, n.1, p.53-58, 1998

10.Del Serrone, P.; Merzachi, C.; Bragaloni, M.; Galeffi, P. Phytoplasma infection of tomato in central Italy. Phytopathologia Mediterranea, Bolonha, v.40, n.2, p.137-142, 2001.

11.Ferire, C. J. S.; Camelatto, D. A cultura da maçã. Brasília : Embrapa, 1994. v.1, 107 p.

12.Gundersen, D.E.; Lee, I.M. Ultrasensitive detection of phytoplasma by nested-PCR assays using two universal primers pairs. Phytophatologia Mediterranea, Bolonha, v.35, n.2, p.144-151, 1996.

13.Jomantiene, R; Davis, RE; Valiunas, D.; Alminaite, A. New group 16SrIII phytoplasma lineages in Lithuania exhibit rRNA interoperon sequence heterogeneity. European Journal of Plant Pathology, Dordrecht, v.108, p.507-517, 2002.

14.Lee, I.M.; Hammond, R.W.; Davis, R.E. Gundersen, D.E. Universal amplification and analysis of pathogen 16S rDNA for identification of mycoplasmalike organism. Phytopathology, St Paul, v.83, n.9, p.834-842, 1993.

15.Lee, I.M.; Gundersen, D.E.; Hammond, R.W.; Davis, R.E. Use of mycoplasmalike organism (MLO) group-specific oligonucleotide primers for nested PCR assays to detect mixed-MLO infections in a single host plant. Phytopathology, St Paul, v.84, n.6, p.559-566, 1994.

16.Lee, I. M.; Gundersem-Rindal, D. E.; Davis, R. E. ; Bartoszyk, I. M. Revised classification scheme of phytoplasmas based on RFLP analyses os 16S rRNA and ribosomal protein gene sequences. International Journal Systematic Bacteriology, Ames, v.48, p.1153-1169, 1998

17.Lemoine, J. ; Thibault, B. Degeneration diseases of Asian pear tree Nashi and $\mathrm{Li}$ (pear vein yellows, pear necrotic spot, apple rubbery wood and apple stem grooving). Phytoma, Paris, v. 407, p.44-46, 1989.

18.Nerone, R.C. Detecção e identificação molecular de fitoplasmas associados ao amarelo da videira. 2004. 46f. Dissertação (Mestrado em Fitopatologia) - Escola Superior de Agricultura "Luiz de Queiroz", Universidade de São Paulo, Piracicaba.

19.Poggi-Pollini, C.; Giunchedi, L.; Filippini, G; Seemuller, E.; Vindimian, E. Etiological studies of apple rubbery wood disease. Acta Horticulturae, The Hague, v.386, p.503-505, 1995.

20.Seemuller E. Diseases caused by mycoplasmas. In: Jone, A.L. ; Aldwinckle E. Compendium of Apple and Pear Disease. Saint Paul: American Phytopathological Society Press, 1991. p. 67-70.

21.Souza, C.H.; Parish, C.L. Apple decline in Brazil. Acta Horticulturae, The Hague, v.309, p.241-243, 1992.

22.Vega, J.; Betti, J.A.; Costa A.S. Estruturas filamentosas no floema de macieira Gala com sintomas de lenho mole. Summa Phytopathologica, Botucatu, v.7, n.1, p.10, 1981. 